\title{
ATUAÇÃO DE ESTUDANTES DE ENFERMAGEM EM UM CENTRO DE ORIENTAÇÃO E ACONSELHAMENTO (COAS)* PARA HIV: RELATO DE EXPERIÊNCIA
}

\author{
Denise Raquel de Souza Cappi** \\ Juliana Giovannetti de Jesus** \\ Lúcia Yasuko Izumi Nichiata*** \\ Renata Ferreira Takahashi****
}

CAPPI, D.R.S.; JESUS, J.G.; NICHATA, L.Y.I.; TAKAHASHI, R.F.T. Atuação de estudantes de enfermagem em um centro de orientação e aconselhamento (COAS) para HIV: relato de experiência. Rev.latino-am.enfermagem, Ribeirão Preto, v. 9, n. 1, p. 66-72, janeiro 2001.

Relata-se a experiência de graduandos de enfermagem num Centro de Orientação e Apoio Sorológico (COAS) para a realização do teste anti-HIV. Objetivos: descrever a experiência; identificar fatores dificultadores e facilitadores na realização do aconselhamento. As dificuldades: o preparo insuficiente para abordar aspectos sobre a sexualidade, a insegurança na tomada de condutas, o preconceito frente a diferentes práticas sexuais, o tempo exíguo para o estabelecimento de vínculos e a ansiedade ao comunicar os resultados positivos. As facilidades: a receptividade da equipe, sua disponibilidade para descrever o funcionamento do serviço, orientar e esclarecer dúvidas surgidas durante o desenvolvimento do trabalho; a realização das palestras, bem como a existência de impressos utilizados no aconselhamento pré e pós teste e a disponibilidade de recursos educativos, como as fitas de vídeo.

UNITERMOS: HIV, AIDS, aconselhamento, enfermagem

\section{OBJETIVOS E JUSTIFICATIVA}

$\boldsymbol{E}_{\text {ste estudo teve como objetivos descrever as }}$ experiências vivenciadas por alunas de graduação da Escola de Enfermagem da Universidade de São Paulo, como voluntárias, num Centro de Orientação e Aconselhamento (COAS) para detecção da infecção pelo $\mathrm{HIV}$, e identificar fatores facilitadores e dificultadores para a realização das atividades de aconselhamento.

Cursando a disciplina "Enfermagem em Saúde Coletiva", com Enfoque em Doenças Transmissíveis, como parte de atividades práticas, prestamos assistência a pessoas portadoras do vírus HIV, em um Centro de Referência e Treinamento de DST/AIDS, durante um período que consideramos insuficiente para responder aos questionamentos acerca do processo de vivenciamento da AIDS.

Perguntávamo-nos, naquele momento, como comunicar o resultado de um exame sorológico para o
HIV. Como abordar e conversar com essas pessoas? Como auxiliar o usuário a enfrentar o resultado? Como são as pessoas que procuram fazer o exame? Estas indagações nos impulsionaram a conhecer melhor as questões envolvidas no diagnóstico da infecção, por meio de um trabalho voluntário em um COAS, sob a orientação de docentes da referida disciplina.

Caracterizada como atividade de extensão universitária, a solicitação para a participação dos alunos foi encaminhada ao Comitê de Ética e Pesquisa da Instituição. Em julho de 1997, viabilizada a possibilidade de nossa atuação voluntária, recebemos um treinamento no próprio serviço, onde desenvolvemos o trabalho, no período de agosto de 1997 a fevereiro de 1998.

\section{OS CENTROS DE ORIENTAÇÃO E ACONSELHAMENTO}

No passado, os modelos prioritários de intervenção em saúde tinham "a persuasão ou a coerção"

\footnotetext{
* A partir de 1997, os COAS passaram a ser denominados Centros de Testagem e Aconselhamento (CTA). No texto optou-se por utilizar a denominação COAS

** Alunas do Curso de Graduação em Enfermagem da Escola de Enfermagem da Universidade de São Paulo

*** Professor Assistente do Departamento de Enfermagem em Saúde Coletiva da Escola de Enfermagem da Universidade de São Paulo. Endereço: Av. Dr. Enéas de Carvalho Aguiar, 419 - 05403-000 - São Paulo - São Paulo - Brasil

**** Professor Doutor do Departamento de Enfermagem em Saúde Coletiva da Escola de Enfermagem da Universidade de São Paulo. Endereço: Av. Dr. Enéas de Carvalho Aguiar, 419 - 05403-000 - São Paulo - São Paulo - Brasil
} 
como alicerces de uma lógica disciplinadora de prevenção, principalmente em relação às "doenças venéreas" (CARRARA, 1994). Hoje, a disseminação das doenças sexualmente transmissíveis (DST) e da infecção pelo HIV e da AIDS tem gerado a necessidade do desenvolvimento de novas e eficazes estratégias de prevenção visando o seu controle. É preciso que se estabeleça uma relação de confiança entre o trabalhador e o usuário do serviço de saúde para que ocorra, de fato, o impacto das ações de prevenção. Uma importante estratégia que vem de encontro com essa necessidade é a prática do ACONSELHAMENTO, que visa ampliar o acesso da população à realização do teste anti-HIV e para a detecção da sífilis, ao mesmo tempo em que busca implementar ações de prevenção da infecção pelo HIV e das DST, seja no âmbito individual quanto coletivo (CENTER FOR DISEASE CONTROL, 1985; BRASIL.MS., 1997 a, b, c).

Foi o Center for Disease Control (CDC) dos Estados Unidos da América o primeiro a utilizar a palavra aconselhamento, numa publicação em que recomendava a realização de atividades que propiciassem a formação de um vínculo entre usuários, no caso específico, doadores de banco de sangue e trabalhadores da saúde, para favorecer a realização do teste anti-HIV e a obtenção de informações sobre o paciente, seus contatos sexuais e o seguimento das orientações em relação a medidas preventivas (CDC, 1985; 1991; KALICHMAN, 1993).

Além dos Bancos de Sangue, os testes para o diagnóstico da infecção passaram a estar disponíveis também em determinados serviços, como as clínicas especializadas para o atendimento de pessoas com DST, nos serviços de atenção aos usuários de drogas endovenosas e em outros que prestassem assistência a grupos, na época, considerados "de risco", como os profissionais do sexo e os homossexuais. Em 1987, os CDC realizaram a primeira revisão da estratégia de aconselhamento em HIV/AIDS, redefinindo os locais de testagem e recomendando a criação de centros específicos para a realização da prática da testagem e do aconselhamento, desvinculados dos serviços que realizavam diagnóstico e tratamento das DST. Essa mudança visava a criação de locais que pudessem oferecer o teste anonimamente e objetivava minimizar a resistência dos usuários em buscar a testagem sorológica (KALICHMAN, 1993).

A Organização Mundial de Saúde definiu Aconselhamento como um diálogo confidencial entre o cliente e o profissional de saúde com o objetivo de capacitar o cliente a lidar com situações estressantes e a tomar decisões pessoais relativas à AIDS, incluindo uma avaliação dos riscos pessoais para as infecções e a promoção de comportamentos preventivos (BRASIL.MS., 1997c).
No Brasil, em 1988, o Ministério da Saúde, por intermédio do Programa Nacional de DST e AIDS, iniciou a criação dos Centros de Orientação e Apoio Sorológico (COAS) para a detecção do vírus HIV e de outras DST, instituindo o aconselhamento como o principal instrumento de intervenção em saúde, visando a prevenção da infecção e a detecção precoce de casos (BRASIL.MS., 1993b).

Os primeiros COAS, implantados nos estados de São Paulo e Rio de Janeiro, tinham como diretrizes; atuar como centro de divulgação de informações sobre a prevenção da infecção pelo HIV, sob a forma de palestras coletivas e consultas individuais; realizar testes gratuitos e anônimos, antes disponíveis apenas em bancos de sangue e laboratórios especializados; oferecer interpretação correta para os testes realizados, seguida de orientação sobre as medidas preventivas cabíveis e encaminhar os indivíduos soropositivos para o atendimento em serviços de atenção primária (BRASIL.MS., 1993a).

Os COAS têm como características principais a acessibilidade, a gratuidade, a confidencialidade e o anonimato, atuando de modo flexível, com agilidade e resolutividade, possibilitando o aconselhamento adequado. Estas características visam ampliar o acesso da população à realização do teste anti-HIV e para a detecção da sífilis, ao mesmo tempo em que buscam implementar a prevenção da infecção pelo HIV e das DST, através do aconselhamento coletivo e individual (BRASIL.MS., $1997 \mathrm{a}, \mathrm{b}, \mathrm{c}$ ).

Estes serviços devem estar localizados em vias de fácil acesso e atuar como referência para a assistência à saúde da população local, podendo ser uma instalação isolada ou estar agregada às Unidades de Saúde, desde que tenha dependências exclusivas para a realização de suas atividades. Devem atender à demanda espontânea $\mathrm{e}$ a encaminhada por outros serviços de saúde (BRASIL.MS., 1997 a, b, c).

Há flexibilidade em relação ao anonimato, podendo ou não existir se o cliente assim o desejar. São ressaltadas as implicações éticas, legais e psicológicas decorrentes da compartilha ou não do diagnóstico da infecção com terceiros. A confidencialidade das informações é garantida, pautando-se nos códigos de ética, por ser condição essencial para o estabelecimento da confiança necessária entre o usuário e o aconselhador (BRASIL.MS., 1997a).

Quanto às características de agilidade e resolutividade, estes serviços devem oferecer ao usuário uma recepção acolhedora, um fluxo interno rápido que resulte em um tempo mínimo de espera para a coleta de sangue, para a disponibilidade rápida dos resultados e para o aconselhamento pré e pós-teste dos exames realizados. Deve dispor ainda de uma rede de serviços 
de referência para a assistência à saúde, visando o acesso imediato ao tratamento e/ou acompanhamento da evolução da infecção pelo HIV dos usuários (BRASIL.MS., $1997 \mathrm{a}, \mathrm{b}, \mathrm{c}$ ).

$\mathrm{O}$ aconselhamento, pauta-se no processo de escuta ativa do cliente, por meio do contato direto, em que o profissional busca promover ou estabelecer uma relação de confiança com ele, oferecendo estratégias que lhe facilitem reconhecer-se como sujeito de sua própria condição de saúde. Tal procedimento busca a mudança das práticas da pessoa infectada que favorecem a transmissão do HIV, além de oferecer apoio emocional diante do impacto do diagnóstico da infecção. Por este motivo, os atendimentos realizados no COAS não se limitam à orientação para a realização do teste e sobre o resultado, mas abrangem outros aspectos sobre a vida sexual da pessoa, esclarecimentos ou apoio necessários em conseqüência da expectativa ou confirmação da infecção pelo HIV (BRASIL.MS., 1997 a, b, c).

A AIDS suscitou a discussão de questões relacionadas com a sexualidade, uso de drogas, a morte, a violência que demandaram a revisão de conceitos sobre o risco de transmissão. Ainda fez aflorar sentimentos envolvendo conteúdos morais, juízos de valor, preconceitos, estigmas e discriminações, nem sempre explícitos e reconhecidos. No seu cotidiano, o trabalhador da saúde, em contato com as pessoas portadoras do HIV, muitas vezes, tem dificuldade de percepção e deparam com estes sentimentos que, associados à ausência de reflexão, fazem com que muitas vezes não consiga desenvolver suas potencialidades no trabalho de aconselhamento (TAKAHASHI, 1997).

Portanto, é preciso, antes de mais nada, reconhecer tais situações, para que vislumbre a possibilidade de se construir uma relação de troca, também de respeito e confiança mútua com o usuário do serviço.

Sem dúvida, a prática do aconselhamento tem contribuído para a humanização da assistência, ao buscar a participação efetiva do usuário. As experiências positivas com o aconselhamento têm subsidiado o planejamento da assistência em outras unidades de saúde que atendem pessoas com DST e HIV/AIDS. Neste sentido, o Programa Nacional de DST/AIDS tem recomendado estender a oferta do aconselhamento para um maior número de pessoas, ampliando a prática para outros serviços de saúde, além dos COAS. Acrescenta ainda que a prática de aconselhamento é considerada, pela Coordenação Nacional de DST e AIDS, um importante elemento para a qualificação dos serviços prestados pelas unidades de Saúde.

\section{CENÁRIO}

Algumas características foram por nós observadas, durante o trabalho, em um COAS do município de São Paulo. Assim, as descrições e as inferências inseridas no texto que se segue correspondem à nossa percepção do serviço, referente a uma atividade voluntária de extensão universitária.

Até fevereiro de 1998, quando encerramos nossa atividade, o COAS, localizado no Centro de Referência e Treinamento em DST/AIDS do Estado de São Paulo, realizava atendimento de segunda à sexta-feira, no horário das 17 às 21:00 horas.

O fluxo do usuário no serviço é iniciado com a inscrição na recepção, seguindo para a sala de espera, onde se assiste a um vídeo educativo e participa de uma palestra sobre DST/AIDS. A orientação individual (préteste) ocorre antes da coleta de sangue e só é realizada caso o cliente a solicite. Após 15 dias, ele retorna para receber o resultado do exame e a orientação denominada "pós-teste".

Por ser o COAS um serviço em que é possível o anonimato do cliente, este pode designar um codinome para sua identificação. Na sala de espera, o cliente preenche um questionário contendo perguntas sobre conhecimentos gerais acerca das DST, situações de risco vivenciadas e principal motivo para a procura do serviço.

$\mathrm{Na}$ sala de vídeo e palestra, são exibidos vídeos educativos sobre DST e AIDS que abordam a forma de contágio e a prevenção, com duração média de uma hora. Em seguida, é realizada uma palestra complementar, em que são abordados o funcionamento do COAS, os exames realizados, o período correto para a sua realização, o período de tempo para a entrega do resultado, os meios de contágio e a prevenção das DST. Preservativos masculinos são distribuídos e explicadas as formas corretas de armazenamento e utilização. Após o término da palestra, os clientes têm oportunidade de esclarecer suas dúvidas. Caso não se sintam à vontade para apresentar seus questionamentos junto ao grupo, é oferecida a possibilidade de serem atendidos individualmente por outro profissional da equipe que esteja disponível ou pelo próprio palestrante.

As conseqüências de um teste positivo para o HIV podem ser potencialmente devastadoras e, em alguns casos, tão imprevisíveis que o paciente deve estar preparado para o resultado. Mesmo que o resultado seja negativo, o fato de se submeter ao teste sugere que a pessoa reconhece estar, de alguma forma vulnerável à infecção, e o aconselhamento é importante como estratégia de redução do risco.

Encerrada esta sessão, é realizada a coleta das amostras de sangue. A pessoa deve: estar ciente de que o teste está sendo realizado, conhecer o seu significado e assumir a responsabilidade de fazer o teste.

Após aproximadamente 15 dias, é realizado o aconselhamento pós-teste, quando é comunicado o 
resultado dos exames. Se positivo, a pessoa é encaminhada para algum serviço de acompanhamento e tratamento próximo à residência. Se negativo, o cliente é novamente orientado, reiterando-se, principalmente, os aspectos de prevenção das DST/AIDS. Após esse procedimento, é informado de que poderá realizar futuras testagens no COAS.

A equipe assistencial é composta por uma enfermeira e um psicólogo, responsáveis pelas palestras pré-teste e pelo aconselhamento individual, e duas auxiliares de enfermagem que coletam o sangue e auxiliam no aconselhamento individual. Além desses profissionais, há um recepcionista que distribui o questionário na sala de espera, localiza os prontuários por ocasião do retorno e agenda os retornos.

Durante o ano de 1997, foram realizados um total de 2987 atendimentos, sendo 1335 palestras e 1652 aconselhamentos individuais.

Nesses atendimentos, a clientela foi constituída por pessoas de diferentes grupos sociais e com diversas práticas sexuais - homossexual, heterossexual, bissexual - como, por exemplo, travestis, prostitutas, garotos(as) de programa, homens casados que mantêm relações extraconjugais, mulheres casadas que descobriram relações extraconjugais de seus maridos, parceiros de soropositivos, universitários, usuários de drogas e casais de namorados que pretendem abolir o uso de preservativo em suas relações. O motivo mais freqüente de busca do serviço é a vivência de situações que configuram risco de exposição ao HIV.

\section{NOSSA VIVÊNCIA}

Acreditamos que nosso aprendizado teve início quando percorremos o fluxo de atendimento como usuárias do serviço. Vivenciar sentimentos como a ansiedade e o medo de um resultado positivo foi fundamental para que pudéssemos identificar, nas condutas dos profissionais, alguns fatores que podem dificultar a relação com o cliente. Destacam-se a preocupação do aconselhador em não impor comportamentos, visando a prevenção das DST/AIDS e não emitir julgamentos acerca do comportamento do cliente. Além disso, a possibilidade de um resultado positivo de DST implicou sentimentos de insegurança em relação à confiabilidade do próprio exame laboratorial, ao significado exato do resultado, às indagações sobre como pode ter ocorrido a contaminação e quais as pessoas envolvidas nos relacionamentos e as conseqüências do resultado na vida de cada pessoa.

Assistir às consultas individuais e aos aconselhamentos coletivos também contribuíram para o nosso aprendizado. As pessoas que chegam a um COAS, o fazem pelas razões mais diversas. Podem estar com alguma suspeita (apresentando algum sintoma, estiveram sob situação que consideram de risco para aquisição de DST e/ou são parceiros de alguém soropositivo), procurando voluntariamente ou ter sido encaminhado por algum serviço de saúde. Outros, sem apresentar suspeita, vêm para esclarecer dúvidas a respeito dessas doenças. Cada atendimento é único, já que cada pessoa traz uma história de vida. Assim, não há "receitas" sobre as formas de se abordar cada caso, embora tenhamos os objetivos definidos para o aconselhamento.

No aconselhamento pré-teste, concentramos esforços no sentido de identificar a vulnerabilidade à infeção pelas DST/HIV e nas razões que levaram o paciente a realizar o teste e o significado do resultado positivo ou negativo. Além disso, avaliávamos o estado geral de saúde, buscando identificar sintomas de infecção pelo HIV ou outras DST. O momento de avaliação dos riscos é delicado, pois há necessidade de conversar sobre assuntos muito íntimos da vida sexual do usuário. Diante das informações, buscávamos avaliar, em conjunto, o grau de risco pessoal dessas infecções.

Como forma de antecipar a possibilidade de um resultado positivo, discutíamos as emoções e ações que poderiam aflorar. Buscávamos ajudá-los a encarar as implicações de um resultado positivo e identificar quais seriam as possibilidades de apoio, principalmente da família e de amigos. O apoio da equipe foi fundamental no esclarecimento de dúvidas e na discussão dos casos atendidos, principalmente no período inicial.

Foi um grande desafio atender o usuário, pois o nosso maior medo era ficar frente à frente com ele e darlhe uma notícia para a qual não estava de fato preparado. Refletimos em conjunto: "quem somos nós para dizer que não temos medo ou não ficamos ansiosas e tensas diante de um resultado de exame que pode modificar completamente a nossa vida".

O fato de os primeiros aconselhamentos terem sido realizados para pessoas com o resultado de sorologia negativo também contribuiu para que pudéssemos superar alguns medos e diminuir ansiedades, em função da possibilidade de ter que interagir com alguém com resultado positivo. Pudemos, nesses aconselhamentos, explorar mais os aspectos relativos à educação e à prevenção das DST. Nestas experiências, pudemos exercitar a discussão com as pessoas que procuraram realizar o teste, em relação a estratégias de redução de risco, direcionando as informações obtidas aos comportamentos específicos do paciente.

Pudemos realizar também alguns atendimentos, cujo resultado fora positivo, nunca sozinhos, sempre em conjunto com os trabalhadores do serviço. $\mathrm{O}$ resultado era dado pessoalmente, de preferência, pelo mesmo 
profissional que fez o atendimento pré-teste. Alguns profissionais abriam o envelope junto com o usuário, buscando demonstrar assim a confidencialidade do resultado. Neste momento, foi significativo avaliar a maneira como a informação foi absorvida. Foi importante a atitude dos trabalhadores ao encorajar a expressão de sentimentos do usuário. Diante do resultado, muitas vezes foi essencial esclarecer novamente o significado do teste. Sem dúvida nenhuma, é um desafio comunicar o resultado positivo, mais ainda ajudar o paciente a alcançar a estabilidade emocional e a aceitar e enfrentar a situação de soropositivo.

Alguns atendimentos ilustram bem nossas dificuldades para a realização do aconselhamento. Um rapaz, encaminhado por um serviço hospitalar por estar apresentando sintomas sugestivos da infecção pelo HIV e que procurara o COAS para submeter-se ao teste. Apesar de pouca idade, 20 anos, já tinha vivido experiências de muito sofrimento. Havia estado preso, usava drogas injetáveis e já vivenciara a perda de conhecidos que morreram de AIDS. De imediato, ficou claro que ele não estava ali somente para esclarecer dúvidas, "ser orientado", mas havia uma necessidade de compartilhar seus medos e anseios. Acolher, nesse primeiro momento, significou ouvir. Disse que tinha uma companheira, grávida de oito meses e uma filha pequena. Relatou que não usava preservativos nas suas relações com esta companheira.

Refletimos sobre a situação daquele jovem ..., as conseqüências da infecção para a sua vida ..., a vulnerabilidade das pessoas ..., a insuficiência de meios para o controle da disseminação do vírus HIV ..., fazendo com que sentimentos de angústia aflorassem frente ao limitado impacto das ações de controle existentes.

Sem dúvida, este atendimento, lidando com a possibilidade de um resultado positivo, nos fez perceber o aconselhamento como um importante instrumento de troca de conhecimentos e sentimentos, na tentativa de superar os conflitos existentes, tarefa que, de forma nenhuma, é realizada facilmente.

Outro atendimento que suscitou inúmeras indagações foi realizado com uma mulher de 23 anos. Procurou o serviço com a finalidade de realizar o teste porque o companheiro estava muito doente, desconfiava que fosse por causa do vírus HIV. Não estava agitada nem transparecia preocupação. Durante o aconselhamento discutimos sobre como estava se sentindo, ela expressou muita raiva frente a situação em si e principalmente a mágoa com o seu companheiro. De imediato sentimos empatia, talvez pela semelhança nas suas características, jovem, estudante, namorando e com as mesmas dúvidas que nós. Foi importante para ela sentir que tínhamos essa aproximação, pois a medida que realizamos o atendimento, foi colocando suas dúvidas e sentimentos.
Uma descoberta importante que influenciou a nossa atuação, até então centrada no diagnóstico de soropositividade, foi perceber que, independentemente do resultado do exame, o aconselhamento é importante e necessário para provocar modificações na vida do usuário, auxiliando-o a avaliar suas possibilidades de risco de aquisição das DST e infecção pelo HIV.

Muitos usuários dos COAS, por exemplo, freqüentam o serviço com uma certa periodicidade, são prostitutas, rapazes de programa, pessoas que podem estar mais vulneráveis à infecção pelo HIV devido a sua maior exposição aos riscos. A realização do teste não é o foco principal de intervenção no COAS, mas visa principalmente o aconselhamento para a tomada de consciência sobre os riscos e as possibilidades de redução de danos causados pelas DST e pelo vírus HIV.

Um atendimento também chamou a atenção, ilustrando a finalidade do COAS em captar pessoas que buscam bancos de sangue para a realização de testes. Um senhor, de 60 anos fazia doação nos bancos de sangue com muita freqüência, objetivando a "testagem" do seu sangue, pois tinha de alguma forma, suspeita sobre a possibilidade de estar com alguma DST ou vírus HIV. Aliás, na nossa vivência em campos de estágio percebemos que esta não é uma prática incomum.

Outra oportunidade de aprendizagem importante foi a realização das palestras em sala de espera. No início, embora tivéssemos conhecimentos suficientes sobre os diversos aspectos relacionados com a infecção pelo HIV e já participado das palestras ministradas pela enfermeira, ainda nos sentíamos constrangidos ao abordar algumas questões sobre a sexualidade, como demonstrar o uso de preservativos em um pênis de borracha e abordar as várias formas de relações sexuais (sexo anal, oral, etc.). Muitas vezes, percebíamos que as pessoas não se sentiam à vontade para interromper com perguntas ou comentários, diante de tantos desconhecidos.

Estas palestras tinham a duração média de 45 minutos e eram tantas as informações a serem transmitidas que questionávamos até que ponto estavam sendo retidas e se de fato estavam sendo incorporadas no cotidiano dessas pessoas. Embora a utilização de palestras como um instrumento de intervenção preventiva venha sendo questionada, por seu caráter pontual, muitas vezes, essa atividade constitui a única forma de acesso à informação sobre a doença (AÇÃO ANTI-AIDS, 1993).

Percebemos que algumas informações fornecidas durante a palestra, podem ser surpreendentes para alguns usuários, como a possibilidade de transmissão do vírus pela prática do sexo oral. Apesar das várias campanhas preventivas da AIDS, percebemos que ainda há muita desinformação, o que nos leva a questionar qual segmento da população tem acesso a estas informações e qual o impacto da intervenção. 


\section{CONSIDERAÇÕES}

A avaliação dessas experiências permitiu identificar alguns elementos que auxiliaram ou dificultaram a nossa atuação. Como elementos dificultadores, tivemos: a existência de preconceitos de práticas e comportamentos sexuais diferentes dos nossos; a organização das atividades do COAS, cuja forma de atendimento dificulta a formação de vínculos entre o cliente e o profissional, uma vez que a interação ocorre em praticamente duas ocasiões; a nossa insegurança, presente, especialmente, no desenvolvimento das primeiras atividades, tanto nas palestras como nos aconselhamentos, dificultando a operacionalização das ações, como, por exemplo, a revelação de sorologias positivas.

Já, como elementos facilitadores, podemos citar: a receptividade da equipe, sua disponibilidade para descrever o funcionamento do serviço, orientar e esclarecer dúvidas surgidas durante o desenvolvimento do trabalho. Além desses, destacamos a realização das palestras, bem como a existência de impressos utilizados no aconselhamento pré e pós teste e a disponibilidade de recursos educativos, como as fitas de vídeo.

Ao vivenciarmos este processo, identificamos algumas necessidades para as quais propusemos ações, visando melhorar a qualidade da assistência prestada. Uma delas diz respeito às mudanças nos instrumentos de coleta de dados utilizados antes e após à realização do teste, de forma a torná-los mais completos e objetivos com maior número de dados acerca do usuário e possibilitar-lhes melhor compreensão dos tópicos a serem preenchidos.

Outra ação proposta compreende a implantação de reciclagens periódicas da equipe assistencial e de outros profissionais que atuam voluntariamente, ou por curto espaço de tempo, no serviço. Sugerimos a abordagem dos seguintes temas: a) reflexão sobre o trabalho em enfermagem: o aconselhamento como um instrumento de intervenção em saúde coletiva; b) conhecimento sobre os aspectos clínicos e epidemiológicos das DST/AIDS; c) implicações e significados das provas sorológicas; d) repercussões da prática, junto às DST/AIDS, entre trabalhadores de saúde e clientes; e) Medidas preventivas de intervenção; f) representação social das DST/AIDS e g) realização da prática de aconselhamento.

Acreditamos também que compartilhar experiências entre a equipe e os alunos pôde acelerar a adaptação destes, provavelmente por tornar mais familiar a realidade de vida dessa clientela e por identificar que mesmo o profissional tem sentimentos como medo, insegurança e angústia.

Essa experiência de atuação no COAS permitenos dizer ainda que parte de nossos questionamentos foram respondidos e os sentimentos de medo e ansiedade na assistência ao soropositivo foram minimizados. Acima de tudo, o mais importante foi conhecer as histórias de vida diferentes da nossa realidade e dificilmente descritas em livros ou em sala de aula, que proporcionaram não só crescimento profissional, mas também aprendizagem de vida.

\section{DESCRIBES THE EXPERIENCE OF NURSING STUDENTS IN A CENTER OF TESTING NA COUNSELING THAT OFFERS ANTI-HIV TEST}

The paper describes the experience of undergraduated nursing students in a Center of Testing and Counseling (CTA), that offers anti-HIV test. There were identifed the facilities and the difficulties faced in the accomplishment of the counseling before and after-test, for five months, aiming to propose strategies to surmount them.

\section{ACTUACIÓN DE ESTUDIANTES DE ENFERMERÍA EN UN CENTRO DE ORIENTACIÓN Y CONSEJERÍA (COAS)* PARA HIV: RELATO DE EXPERIENCIA}

Se relata la experiencia de estudiantes de enfermería en un Centro de Orientación y Apoyo (COAS) para la realización de la prueba anti-HIV. Objetivos: Describir la experiencia, identificar factores limitantes y facilitadores en la realización de la consejería. Las dificultades: La preparación insuficiente para abordar aspectos sobre la sexualidad, la inseguridad en la toma de conductas, el preconcepto frente a diferentes prácticas sexuales, el poco tiempo para el establecimiento de vínculos y la ansiedad al comunicar los resultados positivos. Las facilidades: La receptividad del equipo, su disponibilidad para describir el funcionamiento del servicio, orientar y establecer dudas surgidas durante el desarrollo del trabajo; la realización de las charlas educativas, así como también la existencia de material impreso utilizado en la consejería antes y después de la prueba y la disponibilidad de recursos educativos, tales como, películas de vídeo. 


\section{REFERÊNCIAS BIBLIOGRÁFICAS}

01. AÇÃO ANTI-AIDS. Boletim Internacional sobre prevenção e controle da AIDS. Rio de Janeiro, n. 19, 1993.

02. BRASIL. Ministério da Saúde. Boletim Epidemiológico AIDS. Brasília, v. 6, n. 1, 1993 a.

03. BRASIL. Ministério da Saúde. Secretaria de Projetos Especiais de Saúde. Coordenação Nacional de DST e AIDS. Normas de organização e funcionamento dos Centros de Orientação e Apoio Sorológico. Brasília, 1993b.

04. BRASIL. Ministério da Saúde. Secretaria de Projetos Especiais de Saúde. Coordenação Nacional de DST e AIDS. Aconselhamento em DST, HIV e AIDS diretrizes e procedimentos básicos. Brasília, 1997a.

05. BRASIL. Ministério da Saúde. Secretaria de Projetos Especiais de Saúde. Coordenação Nacional de DST e AIDS. O aconselhamento no contexto das DST e HIV/AIDS. Brasília, 1997b.

06. BRASIL. Ministério da Saúde. Secretaria de Projetos Especiais de Saúde. Coordenação Nacional de DST e AIDS. Manual de controle das doenças sexualmente transmissíveis. Brasília, 1997c.
07. CARRARA, S. A AIDS e a história das doenças venéreas no Brasil: de finais do século XIX até os anos vinte. In: PARKER, R. (org.). A AIDS no Brasil. Rio de Janeiro: ABIA, 1994. p. 273306.

08. CENTER FOR DISEASE CONTROL (CDC). Provisional public health service inetr-agency recommendations for screening Donated blood and plasma for antibody to the virus causing acquired immunodeficiency syndrome. MMWR, v. 34, p. 1-5, 1985.

09. CENTER FOR DISEASE CONTROL. Publicy funded HIV counseling and testing United States. MMWR, n. 40, p. 666-9, 1991.

10. KALICHMAM, A.O. Vigilância Epidemiológica de AIDS: recuperação histórica de conceitos e práticas. São Paulo, 1993. Dissertação (Mestrado) - Faculdade de Medicina, Universidade de São Paulo.

11. TAKAHASHI, R.F. A singularidade e a sociabilidade de vivenciar a "TuberculAIDS": a morte anunciada. São Paulo, 1997. Tese (Doutorado) - Escola de Enfermagem, Universidade de São Paulo. 